\title{
Crystal structure of the HGF $\beta$-chain in complex with the Sema domain of the Met receptor
}

\author{
Jennifer Stamos ${ }^{1,3}$, Robert A Lazarus ${ }^{1}$, \\ Xiaoyi Yao ${ }^{1,4}$, Daniel Kirchhofer ${ }^{2}$ \\ and Christian Wiesmann ${ }^{1, *}$
}

${ }^{1}$ Department of Protein Engineering, Genentech Inc., South San Francisco, CA, USA and ${ }^{2}$ Department of Physiology, Genentech Inc., South San Francisco, CA, USA

The Met tyrosine kinase receptor and its ligand, hepatocyte growth factor (HGF), play important roles in normal development and in tumor growth and metastasis. HGFdependent signaling requires proteolysis from an inactive single-chain precursor into an active $\alpha / \beta$-heterodimer. We show that the serine protease-like HGF $\beta$-chain alone binds Met, and report its crystal structure in complex with the Sema and PSI domain of the Met receptor. The Met Sema domain folds into a seven-bladed $\beta$-propeller, where the bottom face of blades 2 and 3 binds to the HGF $\beta$-chain 'active site region'. Mutation of HGF residues in the area that constitutes the active site region in related serine proteases significantly impairs HGF $\beta$ binding to Met. Key binding loops in this interface undergo conformational rearrangements upon maturation and explain the necessity of proteolytic cleavage for proper HGF signaling. A crystallographic dimer interface between two HGF $\beta$ chains brings two HGF $\beta$ :Met complexes together, suggesting a possible mechanism of Met receptor dimerization and activation by HGF.

The EMBO Journal (2004) 23, 2325-2335. doi:10.1038/

sj.emboj.7600243; Published online 27 May 2004

Subject Categories: structural biology; signal transduction

Keywords: hepatocyte growth factor; Met receptor tyrosine kinase; ligand-receptor complex; Sema domain; serine protease

\section{Introduction}

The receptor tyrosine kinase Met, and its ligand, hepatocyte growth factor (HGF, also called scatter factor), have been implicated in promoting the invasive growth of many tumor types due to inappropriate activation of Met function (Trusolino and Comoglio, 2002; Birchmeier et al, 2003; Jankowski et al, 2003; Nardone et al, 2003). This activation can arise from a variety of sources, but in each case the Met receptor activates signaling cascades that normally function

\footnotetext{
*Corresponding author. Department of Protein Engineering, Genentech Inc., 1 DNA Way, South San Francisco, CA 94080, USA.

Tel.: + 1650225 7484; Fax: + 1650225 3734; E-mail: chw@gene.com ${ }^{3}$ Present address: Department of Molecular and Cellular Physiology,

Stanford University, Stanford, CA 94305, USA

${ }^{4}$ Present address: Department of Chemistry and Biochemistry,

Texas Tech University, Lubbock, TX 79409, USA
}

Received: 25 February 2004; accepted: 29 April 2004; published online: 27 May 2004 to organize groups of cells into branching, tubular structures that are present in a variety of organs (Montesano et al, 1991; Sonnenberg et al, 1993; Rosen et al, 1994; Trusolino and Comoglio, 2002; Zhang and Vande Woude, 2003). Its role in the invasiveness of many cancers makes it an attractive target for therapeutics (Ma et al, 2003). However, many unanswered questions remain about how the ligand HGF binds to Met and induces its tyrosine kinase cascade and thus leads to a biological response.

The Met receptor is part of a larger family of growth factor receptors with identical domain architecture that includes the Ron and Sea receptors (Ronsin et al, 1993; Huff et al, 1993). The extracellular portions of Met family members are composed of three domain types. The N-terminal 500 residues fold into a Sema domain, which shares sequence homology with domains found in the semaphorin and plexin families of neural development proteins (Winberg et al, 1998). As reported recently, Sema domains form a seven-bladed $\beta$ propeller structure (Antipenko et al, 2003; Love et al, 2003). Met undergoes proteolytic cleavage within the Sema domain during normal processing, although the role for this remains unclear since cells that are unable to cleave Met show normal levels of Met activation upon ligand binding (Komada et al, 1993). A PSI domain, spanning about 50 residues and containing four disulfide bonds, follows the Sema domain. In addition to the Met receptor family, PSI domains are also found in the plexins, semaphorins, and integrins, hence its name (Bork et al, 1999). In Met, the PSI domain is connected via four IPT domains to the transmembrane helix and the kinase domain in the intracellular portion of the receptor. IPT domains are related to immunoglobulinlike domains and are named after their presence in plexins and transcription factors (Takagi et al, 1995).

HGF is a member of the plasminogen-related growth factor family and contains 728 residues. It is secreted as an inactive single-chain precursor, which is proteolytically processed to form the biologically active disulfide-linked $\alpha / \beta$-heterodimer (Nakamura et al, 1989; Hartmann et al, 1992; Kataoka et al, 2003). The $\alpha$-chain folds into an $\mathrm{N}$-terminal domain ( $\mathrm{N}$ domain), followed by four Kringle domains. The $\beta$-chain starts with residue Val495 and is homologous to the chymotrypsin family of serine proteases, which, like HGF, is activated by a proteolytic cleavage event (Perona and Craik, 1995; Hedstrom 2002). However, HGF lacks any proteolytic activity (Lokker et al, 1992), consistent with the absence of the key serine and histidine residues that comprise the 'catalytic triad' Asp[c102]-His[c57]-Ser[c195] ([chymotrypsinogen numbering]) required for catalytic activity in serine proteases.

Comparisons of the biologically active, two-chain HGF, and the inactive single-chain HGF precursor, have shown that both forms of HGF bind Met with similar affinity, but only the cleaved, mature form of HGF is able to activate Met (Hartmann et al, 1992; Lokker et al, 1992). In addition, various $\mathrm{C}$-terminally truncated fragments of the $\alpha$-chain 
(termed NK1, NK2, or NK4 depending on the number of Kringle domains retained) bind Met; in some cases, they act as potent antagonists of Met receptor function (Chan et al, 1991; Cioce et al, 1996; Date et al, 1997). Interestingly, NK1, which harbors the high-affinity binding site for Met, does not bind the receptor in the absence of heparin (Lietha et al, 2001). Studies involving the crosslinking of Met receptors by a variety of specific antibodies to its extracellular domain have demonstrated that simple dimerization of Met is sufficient for activation (Prat et al, 1998). Based on these characteristics, the fundamental mechanism for Met dimerization remains unclear. Does the HGF $\beta$-chain interact directly with Met, and if so, how? What is the stoichiometry in the signaling complex between HGF and Met? What role does cleavage play in conferring HGF with its ability to dimerize Met?

To answer these questions, the HGF $\beta$-chain alone, designed to mimic the $\beta$-chain of the cleaved form of full-length HGF, was expressed and characterized. We show that the HGF $\beta$-chain itself binds to Met, albeit with low affinity. We expressed the Sema and PSI domains of the Met receptor and co-crystallized this protein with the HGF $\beta$-chain. The crystal structure reveals a seven-bladed $\beta$-propeller structure for the Met Sema domain and a chymotrypsin-like serine protease fold for HGF $\beta$, where the Met-binding interface on HGF $\beta$ is the same region that serine proteases use to bind their substrates or inhibitors. Mutating HGF $\beta$ residues that are located in the binding site seen in the crystal structure significantly impairs HGF $\beta$ binding to Met. This suggests a mechanism whereby, as found with proteases, the N-terminus of the matured HGF $\beta$-chain inserts into the core and induces conformational changes that confer optimal binding ability to Met. Intriguingly, in the crystal-packing arrangement observed here, the $\beta$-chain forms a symmetric dimer, utilizing $\mathrm{N}$ terminal residues to form the interface. This dimer suggests an unexpected, yet appealing dimerization mechanism of fully matured HGF for Met.

\section{Results and discussion}

\section{Binding of HGF $\beta$ to Met}

HGF acquires biological activity upon proteolytic conversion of the single-chain zymogen-like precursor form into its protease-like two-chain form (Hartmann et al, 1992; Lokker et al, 1992). Although HGF mutants lacking the $\beta$-chain (NK4) possess no agonist activity, they still bind with high affinity. In full-length, mature HGF, the $\alpha$ - and $\beta$-chains are covalently linked by a disulfide bridge putatively formed between Cys487 and Cys604 (Donate et al, 1994). To prevent artificial dimerization of HGF $\beta$-chains during purification and crystallization, Cys604 was replaced with serine. Direct binding studies show that HGF $\beta$ binds to the extracellular domain of Met (Met ECD), with a $K_{\mathrm{d}}$ of $90 \mathrm{nM}$ calculated from relatively fast association $\left(k_{\mathrm{on}}=1.2 \times 10^{5} \mathrm{M}^{-1} \mathrm{~s}^{-1}\right)$ and dissociation $\left(k_{\text {off }}=0.011 \mathrm{~s}^{-1}\right)$ rate constants (Figure 1$)$.

\section{Quality of the crystal structure}

For crystallization, we used a construct of the Met receptor that contained residues 25-567 and a C-terminal $\mathrm{His}_{8}$ tag. In addition, the cleavage site after residue Arg308, present in the Met receptor family but not in the Sema domain of the

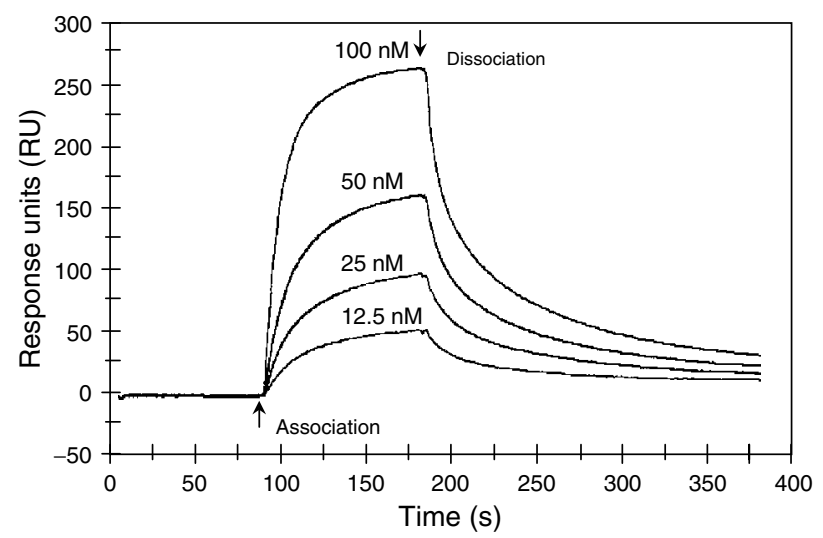

Figure 1 Binding of HGF $\beta$ to the extracellular domain of Met using surface plasmon resonance. Arrows indicate the onset of the association and dissociation phases for a series of concentrations of HGF $\beta$.

Table I Data collection and refinement statistics

\begin{tabular}{lc}
\hline Data collection & \\
Resolution $(\AA)$ & $50-3.3(3.42-3.3)^{2}$ \\
$R_{\text {sym }}$ & $0.054(0.377)^{\mathrm{a}}$ \\
Number of observations & 90034 \\
Unique reflections & 25821 \\
Completeness (\%) & $99.4(99.9)^{\mathrm{a}}$ \\
& \\
Refinement & \\
Resolution $(\AA)$ & $30-3.3$ \\
Number of reflections & 24952 \\
Final $R^{\mathrm{c}}, R_{\text {free }}(F>0)$ & $0.218,0.277$ \\
Number of residues & 727 \\
Number of solvent molecules & 0 \\
Number of non-H atoms & 5728 \\
Rmsd bonds $(\AA)$ & 0.013 \\
Rmsd angles $($ deg) & 1.6 \\
\hline
\end{tabular}

${ }^{\mathrm{a}}$ Numbers in parentheses refer to the highest resolution shell.

${ }^{\mathrm{b}} R_{\mathrm{sym}}=\sum|I-\langle I\rangle| / \sum I .\langle I\rangle$ is the average intensity of symmetryrelated observations of a unique reflection.

${ }^{\mathrm{c}} R=\sum\left|F_{0}-F_{\mathrm{c}}\right| / \sum F_{0}$. $R_{\text {free }}$ is calculated as $R$, but for $5 \%$ of the reflections excluded from all refinement.

semaphorins or plexins, was replaced with a thrombin cleavable site. This exchange (residues 304-308 were exchanged from KRKKR to LVPRG) was introduced since native Met expressed in insect cells was partially cleaved and inhomogeneous. Mutation of the cleavage site allowed for the production of homogeneous protein, and the site was left uncleaved for crystallization. The complex of the HGF $\beta$ chain and the Met fragment was formed in solution, purified using size exclusion chromatography, and set up for crystallization trials.

The resulting crystals diffracted to 3.3 Å resolution (Table I) and have one full complex containing one Met fragment and one HGF $\beta$-chain in the asymmetric unit. The structure was refined to an $R$-value of $21.8 \%\left(R_{\text {free }} 27.7 \%\right)$ with good geometry. Of the 628 non-glycine and non-proline residues, $97.6 \%$ have their main-chain torsion angles in the 'mostfavored' or the 'additionally allowed' regions of the Ramachandran plot (Laskowski et al, 1993). The refined model includes residues 495-722 of HGF and residues $40-301,311-377,382-400$, and $414-564$ of Met. Although a number of glycosylation sites displayed electron density, none of the sugars were modeled into the structure. 


\section{HGF $\beta$-chain structure}

The $\beta$-chain of HGF shares ca. $40 \%$ sequence identity with the protease domain of plasmin, a chymotrypsin-like serine protease. Structurally, these enzymes can be described as globular proteins composed of two antiparallel $\beta$-barrel domains (Figure 2A). HGF, like serine proteases, is expressed as a zymogen-like precursor. For serine proteases, structural studies have shown that insertion of the $\mathrm{N}$-terminus resulting from the maturation process leads to allosteric rearrangements within the binding pocket for the protease substrate (Perona and Craik, 1995; Hedstrom, 2002). The newly formed $\mathrm{N}$-terminus forms a salt bridge with a nearby aspartate, which leads to the formation of the oxyanion hole via the backbone amides of two neighboring residues, and the creation of part of the S1 pocket (Figure 2). The 'activated' form of the HGF $\beta$-chain, as presented here, is very similar to the mature form of serine proteases: superposition with plasmin (PDB- code 1BML) yields an rmsd of about $1.3 \AA$ for $212 \mathrm{C}_{\alpha}$ pairs. Superposition of HGF $\beta$-chain and plasminogen (PDBcode 1QRZ) reveals differences in their 'activation domains' (Freer et al, 1970) and only $198 \mathrm{C}_{\alpha}$ pairs can be aligned well.

As with serine proteases, in HGF the N-terminal amine of Val495 is inserted into the core of the C-terminal $\beta$-barrel and forms a salt bridge with the carboxylate of Asp672, corresponding to Asp [c194] in plasmin. The HGF region corresponding to the serine protease 'activation domain' (Freer et al, 1970; Huber and Bode, 1978) forms part of the binding surface with Met (see below). Therefore, proper positioning of the residues that interact with Met requires maturation of single-chain HGF.

After maturation, the $\alpha$ - and $\beta$-chains of HGF remain connected via a disulfide bond. Based on alignments of the Kringle domains K1-K4 of HGF and macrophage-stimulating protein (MSP), the two cysteine residues responsible for the formation of this disulfide bond were identified as Cys487 on the $\alpha$-chain of HGF and Cys604 on the $\beta$-chain (Donate et al, 1994). The crystal structure, however, raises the possibility of an alternative cysteine residue as the anchor for the HGF $\alpha$ chain. The HGF $\beta$-chain has two cysteine residues that do not have partners for the formation of disulfide bridges within the $\beta$-chain. Neither is conserved in plasmin or MSP and both are located on the periphery of the protein and are at least partially solvent exposed; either could form a disulfide bond with the $\alpha$-chain, while the other remains unpaired. The superposition of the plasmin structure that contains part of the $\alpha$-chain (Figure $2 \mathrm{~B}$ ), and the HGF $\beta$-chain structure presented here, shows that the distance between the $\mathrm{C}$ terminus of the plasmin $\alpha$-chain and Cys604 of the HGF $\beta$ chain is $27 \AA$ and thus only slightly shorter than the respective distance between the plasmin $\alpha$-chain and Cys561 (33 $\AA$ ) (Figure 2B). In addition, the sequence alignment between plasmin, MSP, and HGF (Figure 2C) shows that the $\alpha$-chain cysteine forming the disulfide bond in plasmin and MSP is 13 and 15 residues away from the cleavage site in those proteins, respectively, but there are only seven residues in HGF to span the distance from Cys487 to the cleavage site. Therefore, due to distance requirements, the C-terminus of the HGF $\alpha$-chain cannot follow the same path on the surface of the $\beta$-chain as it does in plasmin or MSP. Further experiments are needed to clarify the interchain disulfide linkage of the mature HGF $\alpha / \beta$-heterodimer.

\section{Structure of Met}

The Sema domain of Met forms a seven-bladed $\beta$-propeller with a diameter of slightly more than $50 \AA$. The overall shape of the domain resembles a funnel with an inner diameter of about $25 \AA$ between main-chain atoms at the wide portion and $10 \AA$ in the narrowest part (Figure 3). Generally, in
A

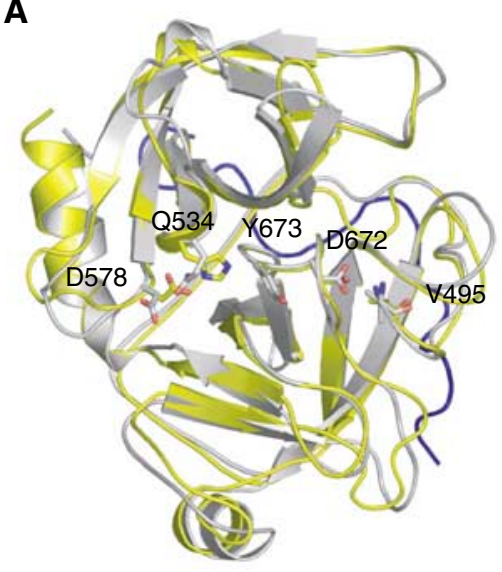

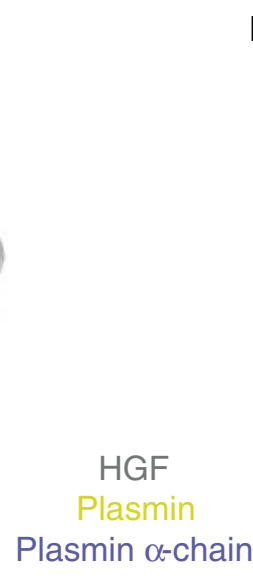

B

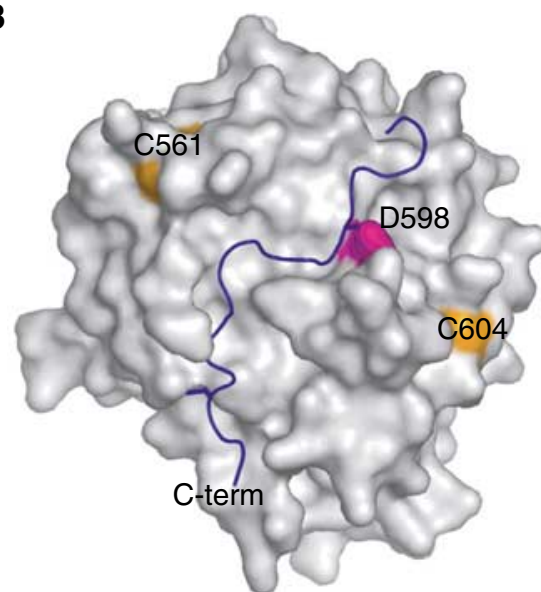

c

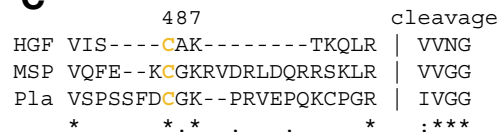

561

LGIH-DVHGRGDEKCKQVLNVSQLVYGP LGTL-FQNPQHGEPSLQRVPVAKMVCGP LGLHREVNP - - ESYSQEIGVSRLFKGP

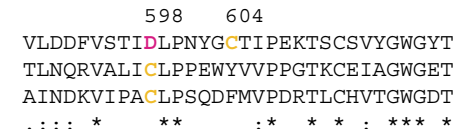

Figure 2 Superposition of HGF $\beta$-chain (gray) and plasmin (yellow). (A) The C-terminal end of the $\alpha$-chain of the plasmin structure is shown as a blue ribbon. Selected side chains are shown as sticks. They include the residues of the catalytic triad in serine proteases, the N-terminal Val495, and Asp672. After maturation, the N-terminus of Val495 is inserted into the core of the protein and forms a salt bridge with the side chain of Asp672. (B) Same superposition rotated $180^{\circ}$ around the $y$-axis. The surface of HGF $\beta$-chain is gray. Cysteines 561 and 604 in HGF are colored orange and Asp598 of HGF is colored purple. The two cysteines on the plasmin $\alpha$-chain are shown as sticks. (C) Sequence alignment of selected regions of HGF, MSP, and plasmin. 

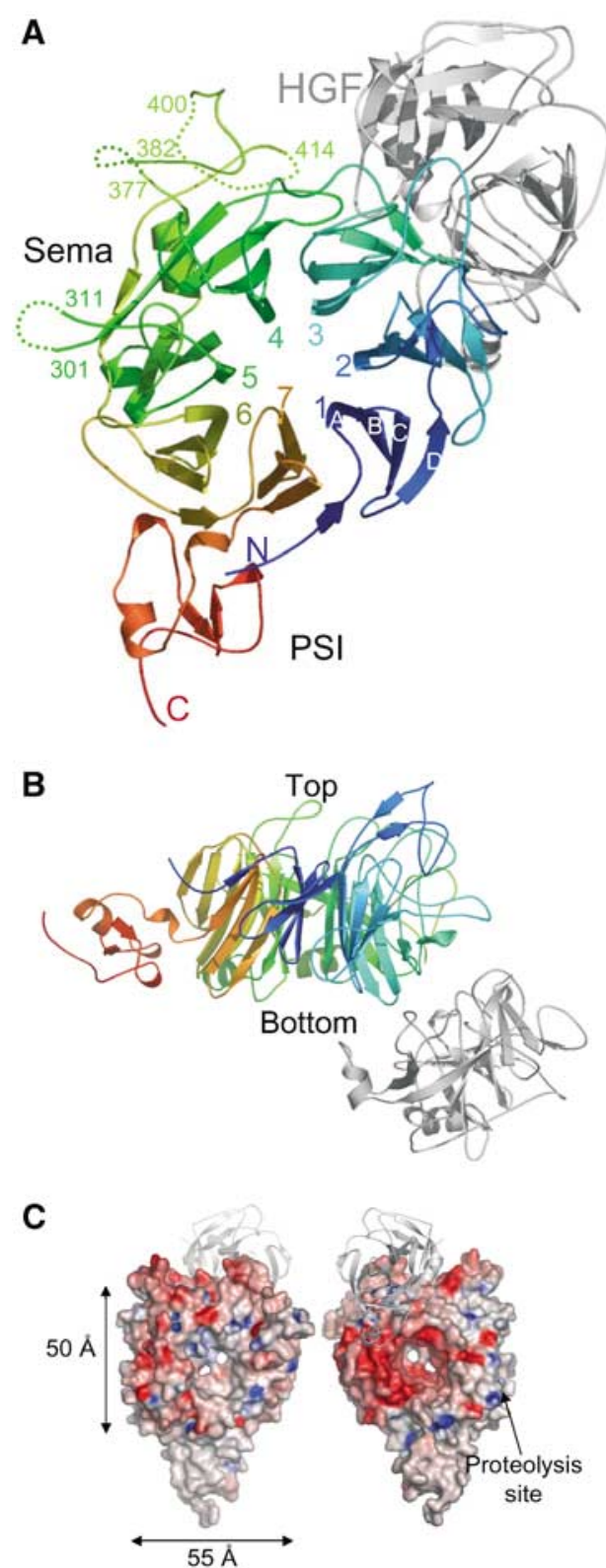

Figure 3 Complex between Met and HGF $\beta$-chain. (A, B) Ribbon representation with HGF $\beta$-chain shown in gray and Met in rainbow colors. The $\mathrm{N}$-terminus of Met is colored blue and the $\mathrm{C}$-terminus is colored red. (A) View of the 'top' side of the propeller. The numbers in the center refer to the blades, and the $\beta$-strands in blade 1 are labeled A-D. Disordered regions are indicated with dotted lines, and the numbers refer to the last and first residues present in the model. (B) Side view of the same complex. All figures were made using Pymol (DeLano, 2002). (C) Surface representation of the Met Sema domain and ribbon diagram of the HGF $\beta$-chain. The surface of Met is colored according to the electrostatic potential, with red and blue indicating negatively and positively charged patches, respectively. The left panel captures the complex in a similar view as (A), and the right panel is a view toward the bottom of the propeller.

$\beta$-propellers, each of the blades is formed by four antiparallel $\beta$-strands with strand $A$ in the center of the propeller followed by strands $\mathrm{B}$ and $\mathrm{C}$, and with strand $\mathrm{D}$ forming the outermost strand of the blade. The blades are arranged in a circular fashion, with the N-terminal strand forming strand D of the last blade, thus closing the propeller and stabilizing the overall structure (Figure $3 \mathrm{~A}$ ). The $\mathrm{AB}$ and $\mathrm{CD}$ loops of each blade of the Met Sema domain form the relatively flat 'bottom' face, and the generally longer BC and DA loops form the 'top' face of the propeller (Figure 3B). In Met, the positions of the sixth and seventh blades are off-center, with blade 7 being closer to the center of the barrel and blade 6 more distant. This gives the domain an overall oval shape.

The $\beta$-propeller of the Met Sema domain is structurally most closely related to the recently reported crystal structures of Sema4D (Love et al, 2003) and Sema3A (Antipenko et al, 2003). With the exception of the D-strands in blades 3 and 5 , the core of Sema4D and the Met Sema domain align well (Figures 4 and 5) and the superposition of residues 40-519 with the Sema domain of Sema4D results in an rmsd of $1.6 \AA$ for 303 atom pairs (Figure 5). The residues that form strand D5 in Sema4A form hydrogen bonds to strand D4 in Met; thus, the fourth blade of Met contains an extra strand, whereas blade 5 is missing its strand $\mathrm{D}$. While the core of both proteins aligns well, the loops contain a number of insertions or deletions and generally adopt very different conformations. For example, the Sema domains of Met and of Sema4D both have an insert of about 20 residues following strand D1. In Met, these residues form a short antiparallel two-stranded $\beta$-sheet, while Sema4D has an $\alpha$-helix (Figures 4 and 5). Of the 24 loops that connect the various strands, only three have no insertions or deletions when comparing Met with Sema4D or Sema3A (Figure 4). Interestingly, both the semaphorins and the Met receptor have their largest insertions between strands C5 and A6; however, these inserts are not related in structure or sequence to each other. In Sema3A, this insert is involved in dimer formation and has been shown to be important for neuropilin binding (Antipenko et al, 2003). In the Met Sema domain, some of the residues within the insert are disordered and not included in our model (see Figure 3). The function of the insert in Met is as of yet unknown, but its proximity to the HGF $\beta$-chainbinding site (see below) suggests that it might be involved in binding to the $\alpha$-chain of HGF.

The loop containing the cleavage site between the $\alpha$ - and $\beta$ chain of Met connects strand D4 to A5; it is disordered in the electron density. After processing of native Met, the $\alpha$-chain, which forms the N-terminal four blades of the Sema domain, and the $\beta$-chain remain connected via at least two disulfide bonds. One disulfide bond is formed between residues Cys298 on strand D4 and Cys363 on C5, and the second is formed between Cys282 (D3) and Cys409. This last cysteine is positioned in a disordered region of the insert after blade 4 . The electron density does not allow tracing of the main chain in this area, but there is sufficient density in the area of the $\mathbf{S} \gamma$ position to suggest that the disulfide bond is at least partially formed. With the exception of the N-terminal Cys26, which is disordered in our crystal structure and has no potential partner in the construct we used for crystallization, all cysteine residues are engaged in disulfide bonds. It is not clear if Cys26 remains unpaired in the context of full-length Met receptor or if it forms a disulfide bond with another cysteine residing in the IPT domains. Besides the two disulfide bonds that covalently connect the $\alpha$ - and $\beta$-chain of the Sema domain, the domain is stabilized by five additional disulfide bridges formed between Cys95-Cys101, Cys98Cys159, Cys133-Cys141, Cys172-Cys175, and Cys385Cys397 (Figure 4). 


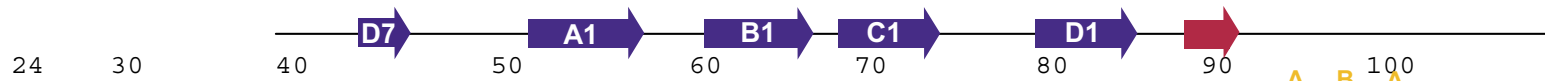

$\begin{array}{lllccccc} & 24 & 30 & 40 & 50 & 60 & 70 & 90\end{array}$ hSema4d FAPIPRITWEHR - - -EVHLVQFHEPD-IYNYSALLLSEDKDTLYIGAREAVFAVNALNISEKQHEVYWKV- - - SEDKKAKCAEKGKSKQ - mSema3a KNNVPRLKLSYKEMLESNNVITFNGLANSSSYHTFLLDEERSRLYVGAKDHIFSFNLVNIK-DFQKIVWPVS - - - YTRRDECKWAGKDIL - - -

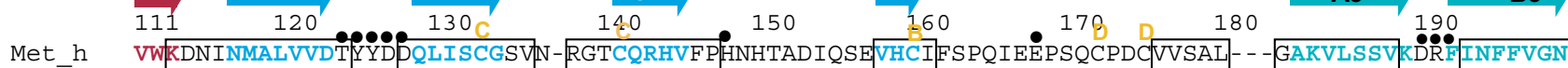
hSema4d TECLNYIRVLOPLSA-- TSLYVCGTNAFBPACDHLNLT- - - - - SFKFLGKN- - - - -EDGKGRCPFDPAHSYTSVMVD- - -GELYSGT mSema3a KECANFIKVLEAYNQ- - THLYACGTGAFHPICTYIEVGHHP-EDNIFKLQDSH- - - - - FENGRGKSPYDPKLLTASLLID- - - GELYSGT

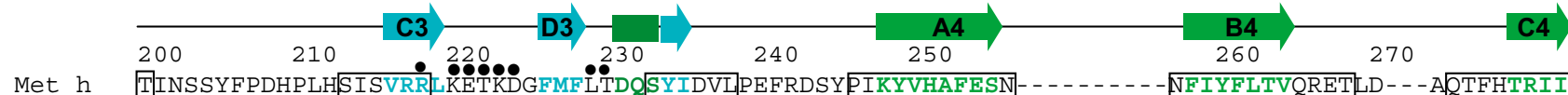
hSema4d SYNFLG- - - SEPIISRNS- - - - - - - SHSPLRTEYA- IPW - LNEPSFVFADVIR]KSPDSPDGEDDRVYFFFTEVSVE-YFVFRVLIPRIA mSema3a AADFMG - - -RDFAIFRTLG - - - - - - -HHHPIRTEQHDSRW-LNDPRFISAHLIP- - ESDNPEDDKVYFFFRENAIDGEHSGKATHARIG

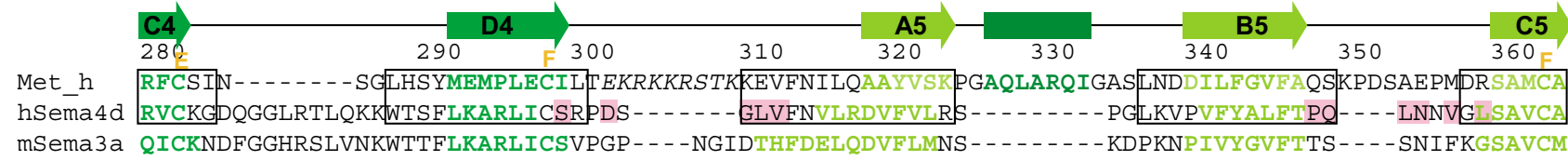
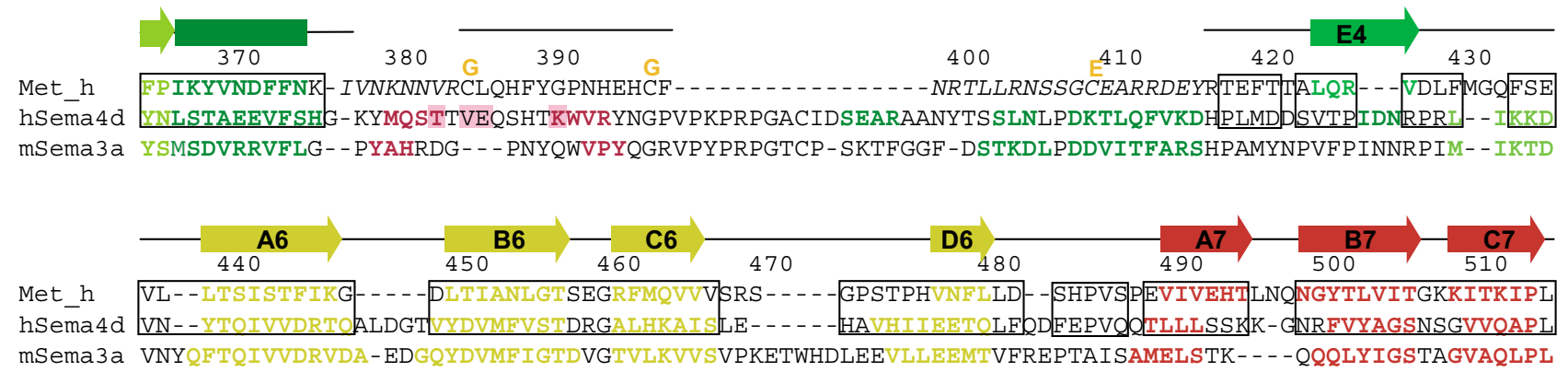

Figure 4 Sequence alignment of the Sema domains of Met, Sema4D, and mouse Sema3A. The secondary structure elements depicted refer to the Met structure; all secondary structure elements are colored. Boxes indicate structurally equivalent positions between Met and Sema4D. Dots above the residues indicate residues that contact HGF. Residues in the dimer interface of Sema4D are marked with purple boxes. Cysteines engaged in disulfide bonds are marked with letters (A-G). Disordered residues are shown in italics. Secondary structure elements that are not part of the propeller core are colored dark red and dark green, representing sheets and helices, respectively.

The surface of the Met Sema domain appears to be mostly negatively charged, especially in the center of the bottom face of the Sema domain (Figure 3C). This surface, which is formed by a 20-residue insertion after strand D in the first blade and includes the rather irregular area of strand $\mathrm{D}$ in the third blade, shows clusters of acidic residues. Monomeric, full-length Met has been shown to bind heparin (Gherardi et al, 2003). In our structure, there are no dominant positively charged patches within the Met Sema domain; however, two arginines are located in the vicinity of the disordered furincleavage site. Together with the six positively charged residues that reside in this loop, these arginines could constitute a potential heparin-binding site.

The last strand of the Sema domain (C7) is followed immediately by the PSI domain. This domain, with dimensions of about $20 \times 15 \AA$, contains four disulfide bridges and is not an integral part of the Sema domain, but rather an independent structural module. The small core of the domain is formed by a helix and a short two-stranded antiparallel $\beta$-sheet, which are connected via a disulfide bond and sandwich the side chain of Trp540. Superposition of this domain with the PSI domain of Sema4D results in an rmsd of $1.6 \AA$ for $41 \mathrm{C}_{\alpha}$ pairs. The relative orientation between the Sema and the PSI domains in the Met and the Sema4D structures, however, is different and requires a rotation of about $40^{\circ}$ for superposition.

\section{The interface between the HGF $\beta$-chain and Met}

The HGF $\beta$-chain binds to the Sema domain of Met at the bottom face of the propeller, and forms contacts with residues that protrude from blades 2 and 3 (Figures 3 and 4). This is unlike other $\beta$-propeller-containing receptors, such as the integrins, which bind their ligands utilizing the top face of the propeller (Xiong et al, 2002). Other Sema domain-containing proteins, such as Sema3A and Sema4D, are also postulated to bind ligands using the top face (Antipenko et al, 2003; Love et al, 2003).

The interface between HGF $\beta$-chain and Met buries a total of $1770 \AA^{2}$ of solvent-accessible surface and is dominated by polar or charge-charge interactions. Of the 20 HGF residues that have more than $10 \AA^{2}$ buried in the interface, six are positively charged, three carry negative charges, and three are aromatic. Even more dramatic, of the 18 residues contributing more than $10 \AA^{2}$ of buried surface to the interface 
A
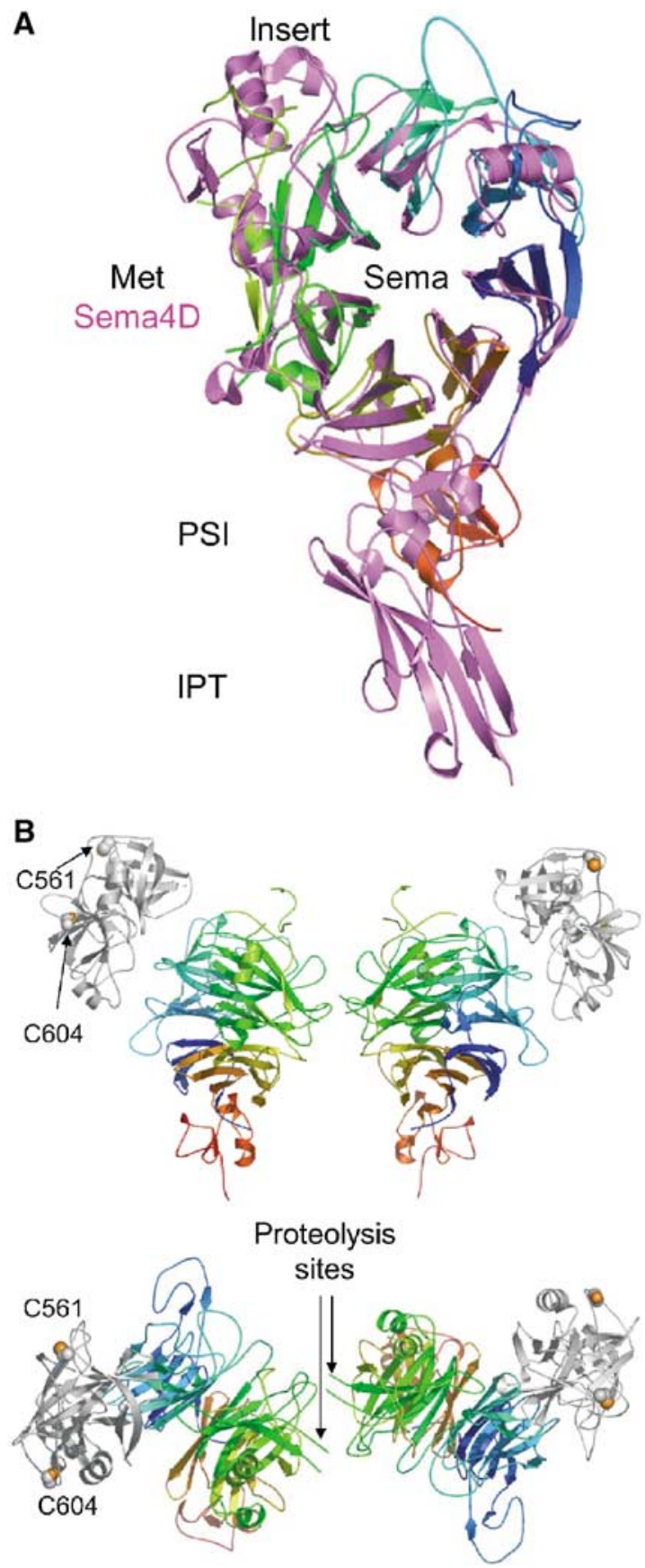

Figure 5 (A) Superposition of Met and Sema4D. Met is shown in rainbow colors as in Figure $3 \mathrm{~A}$, and Sema4D in purple. Note the structural similarities within the $\beta$-propellers and the differences in the insertions. The topology of the PSI domains in both structures is identical, but the relative orientation in comparison to the Sema domains is rather different. (B) Model of a potential Met dimer based on the dimer of Sema4D and the superposition shown in Figure 5A. The interface between the two molecules forming the Sema4D dimer buries approximately $2500 \AA^{2}$. The respective interface in Met would be much smaller due to the different conformation of the loops forming the dimer interface in Sema4D. Residues shown as spheres represent Cys604 and Cys561, the potential disulfide partners of Cys487 in the $\alpha$-chain of HGF.

on the Met side, six carry negative charges, four are positively charged, and three are aromatic. The combined buried surface of the hydrophobic residues Ala, Val, Leu, Ile, Met, and Phe amounts to a mere $145 \AA^{2}$, while the charged residues Asp, Glu, Lys, Arg, and His are responsible for more than
$1000 \AA^{2}$ of buried surface. The resolution of the structure presented here does not allow for the detailed discussion of hydrogen bonds; however, the position of the side chains suggests the presence of at least seven charged interactions between Met and the HGF $\beta$-chain.

On HGF $\beta$, residues analogous to those responsible for substrate binding and catalysis in related serine proteases form most of the interactions with Met. Serine proteases bind linear peptide sequences in the active site and form hydrogen bonds to the main-chain atoms to position a specific peptide bond for proteolytic cleavage. In contrast, the HGF $\beta$-chain binds to a series of protruding polar side chains from Met, which originate mainly from three separate loops (Figure 6B). The first of these loops includes residues 124-128 and connects strands A2 and B2 of Met. This loop contains two tyrosines that are in the core of the binding interface and pack against Arg695 of HGF. The second loop of Met that contacts HGF $\beta$-chain contains residues Asp190, Arg191, and Phe192 and connects A3 and B3. Asp190 of Met forms charged interactions with Arg533 of HGF. The side chain of Arg191 of Met packs against Val692 and Pro693 of HGF with its hydrophobic portion, and in our model is in hydrogen-bonding distance to the side chains of Glu656 and Asp578 with its guanidinium group. This Asp578 corresponds to aspartic acid [c102] in the catalytic triad of the related serine proteases. Furthermore, the backbone of this loop forms hydrophilic interactions with Gln534, the residue homologous to the histidine [c57] of the protease catalytic triad.

The third segment contributing to the interface also includes strand $\mathrm{D}$ in the third blade of the propeller, an area that deviates from the classical 'propeller fold'. Strand D is interrupted and has a short helical insert within its strand. This unusual conformation presents a number of residues toward the surface of the HGF $\beta$-chain. The most prominent interaction formed by this loop involves Glu221, which extends its side chain toward what would be the S1-binding pocket in serine proteases (Figures 6 and $7 \mathrm{~A}$ ). The carboxylate of Glu221 forms a network of polar interactions with the side chain of Tyr673 (corresponding to Ser [c195] of the catalytic triad in proteases) and the backbone amide of Gly696 (Figure 7A); however, unlike in serine proteases, where the $\mathrm{S} 1$ pocket is filled by the specificity-determining P1 residue, it does not penetrate deeply into the S1 pocket. As a result of the exchange of Ser to Tyr in position 673 [c195], the entrance of the $\mathrm{S} 1$ pocket is much smaller than in related serine proteases. Glu221 projects toward the entrance of the S1 pocket from a different angle when compared to a complex between trypsin and bovine pancreatic trypsin inhibitor (BPTI), and does not fill the pocket (Figures 6B and 7A). A large cavity, presumably filled with a number of water molecules, remains in HGF $\beta$-chain.

\section{Mutational studies of HGF $\beta$ binding to Met}

The role of several HGF $\beta$ residues located in the active site region' in related serine proteases has been studied (Lokker et al, 1992). Specifically, residues Y673 and V692 were mutated to serine and the binding affinity and biological activity of both mutants were determined. In their study, neither mutant showed a decrease in binding affinity towards Met in the context of two-chain HGF, yet the biological activity of both mutants was significantly impaired. In the crystal structure, Y673 and V692 are in close contact with the 

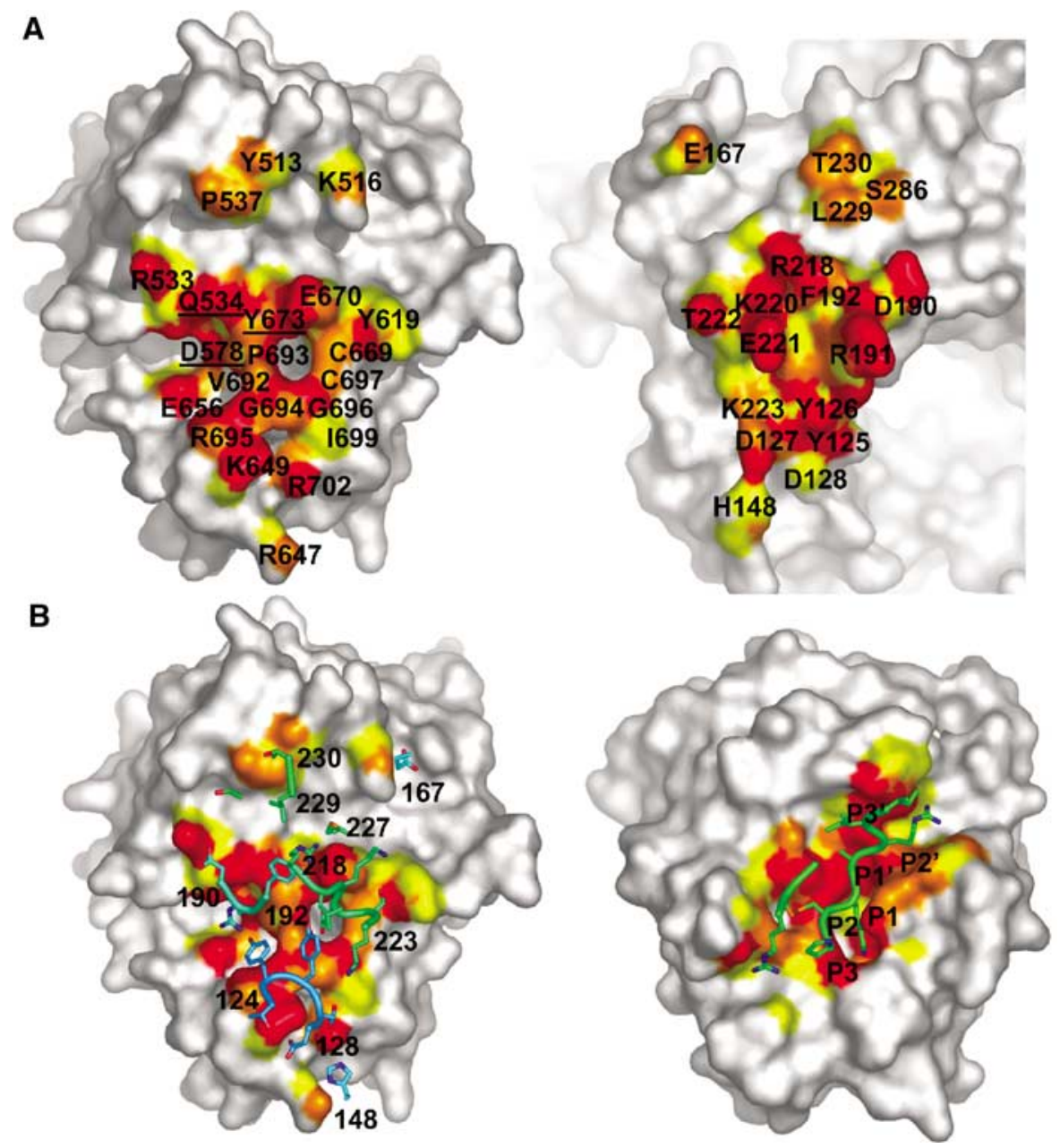

Figure 6 Surface presentations. (A) Open book view of the interface. Atoms closer than 3.5, 4.0 or $4.7 \AA$ to any atom of the binding partner are colored red, orange, and yellow, respectively. Contact residues are labeled. Left side: HGF; right side: Met. The three underlined numbers indicate the residues that form the catalytic triad in serine proteases. (B) Differences in binding mode between HGF:Met and trypsin:BPTI (PDB code 2PTC). Orientations of HGF and trypsin are similar to the view in Figure 3. Left: HGF $\beta$-chain:Met complex. Contacting residues of Met are shown as sticks and colored as in Figure 3, numbers refer to Met. Right: trypsin:BPTI complex. Contacting residues of BPTI are shown as sticks.

Met Sema domain, with Y673 located in the center of the Met-binding interface and forming part of the $\mathrm{S} 1$ pocket (Figure 7A). We expressed and purified two HGF $\beta$ mutants, Y673A and V692A, to investigate their contributions to Met binding in the context of the HGF $\beta$-chain alone. Both mutants were tested in a competition ELISA with biotinylated HGF $\beta$ binding to Met-IgG (Figure 7B). In these assays, HGF $\beta$ competed with an $\mathrm{IC}_{50}$ of $0.55 \pm 0.38 \mu \mathrm{M}(n=16)$, whereas the $\mathrm{IC}_{50}$ for V692A was over 50 -fold higher and Y673A did not compete for Met binding at all. Thus, the functional binding data are in excellent agreement with the HGF $\beta$ 'low-affinity' binding site revealed in the crystal structure. Comprehensive mutational analysis of the $\beta$ chain in HGF and HGF- $\beta$ further supports the structural and functional importance of this interface (D Kirchhofer and R Lazarus, in preparation).

\section{Models for receptor activation}

One goal of our study was to derive a model for HGFmediated Met receptor activation. Little is known about the signaling complex itself, and details of this interaction, such as the stoichiometry between ligand and receptor, have been elusive.
The structure and binding data presented here show unambiguously that Met binds to the $\beta$-chain of HGF and how it does so. However, the exact role this interaction plays in Met activation remains uncertain. Two general models of how HGF can lead to Met dimerization have been suggested (Miller and Leonard, 1998). One of these models follows the growth hormone paradigm (de Vos et al, 1992), where one HGF molecule binds to two different Met receptors with different affinities to form the 2:1 signaling complex. The other model suggests that two 1:1 complexes of Met and HGF are dimerized either via heparin or an alternative mechanism to form stable $2: 2$ complexes.

In our study, complexes of HGF $\beta$-chain and the Met Sema domain were purified from individual components via size exclusion chromatography. The $K_{\mathrm{d}}$ determined for HGF $\beta$ binding to the Met ECD was ca. $90 \mathrm{nM}$, indicating that HGF $\beta$ has low-affinity binding for Met. The study presented here characterizes this low-affinity binding interaction between HGF and Met, which can occur even in the absence of heparin. The high-affinity binding interaction involves the $\alpha$-chain of HGF, in particular the NK1 fragment (Lokker et al, 1992), heparin (Lietha et al, 2001), and a thus far uncharacterized binding site on Met. Our studies are consistent with 

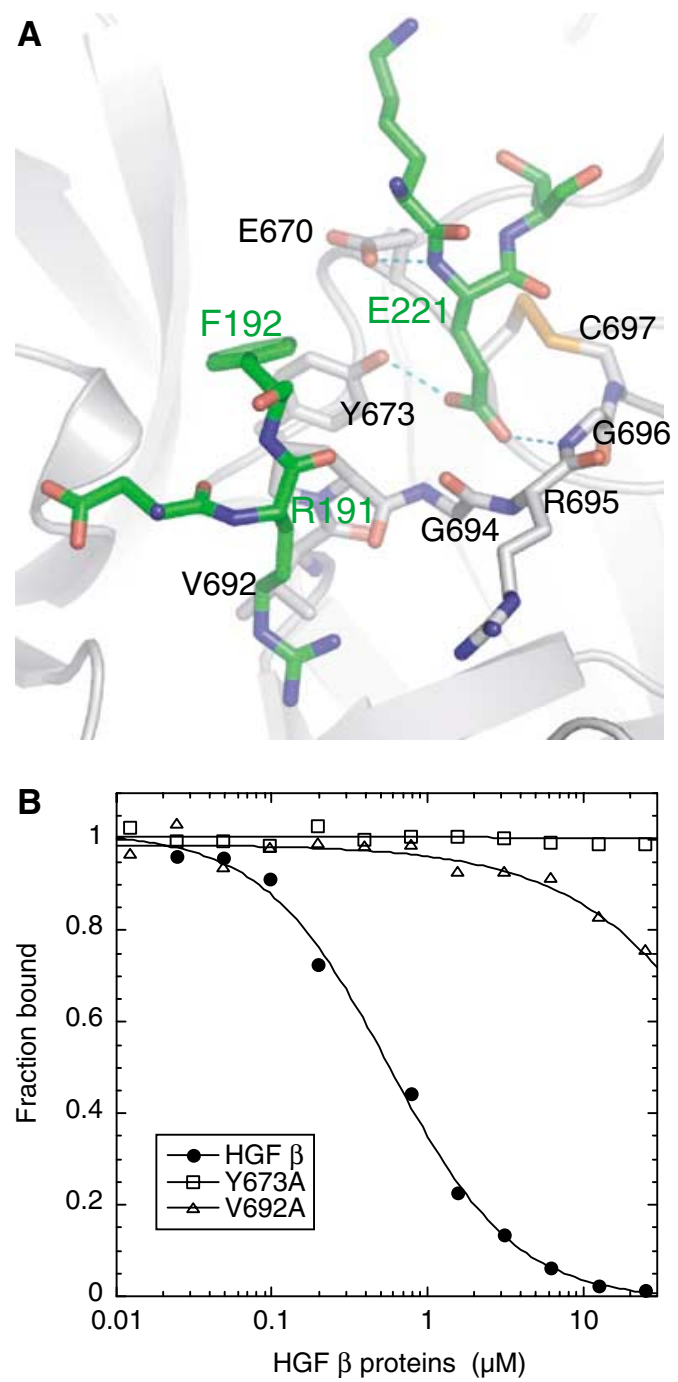

Figure 7 The 'active site region' of HGF $\beta$. (A) The 'S1-pocket' of HGF $\beta$. Selected residues that form the 'S1 pocket' of HGF $\beta$ are shown as sticks with gray carbons. Glu221 and selected residues of Met are depicted and labeled in green. Cyan dotted lines indicate potential hydrogen bonds. (B) HGF $\beta /$ Met-IgG competition ELISA. Competition binding of immobilized Met-IgG with $250 \mathrm{nM}$ maleimide-coupled biotinylated wild-type HGF $\beta$ and unlabeled HGF $\beta$ $(\bullet), \operatorname{HGF} \beta$ Y673A ( $\square)$, and HGF $\beta$ V692A $(\triangle)$.

the observation that single-chain HGF can bind Met via the high-affinity binding site contained in its N-terminal portion, yet cannot signal (Lokker et al, 1992). For signaling, maturation of HGF is required. This leads to rearrangements in the activation domain of HGF $\beta$, the formation of the low-affinity binding site, and the reorientation of the $\beta$-chain of HGF relative to its $\alpha$ chain. This model may be valid for the closely related Ron/MSP system. Like HGF, single-chain MSP can bind to its receptor Ron, but is only able to signal in its matured two-chain form. Interestingly, and in contrast to HGF, the high-affinity binding site in MSP is contained within its $\beta$-chain, while the low-affinity binding site resides in its $\alpha$-chain (Danilkovitch et al, 1999).

Our study clearly shows that the low-affinity interaction between HGF- $\beta$ and Met is sufficient for 1:1 complex formation. Furthermore, recent studies employing analytical ultracentrifugation and light-scattering experiments indicate that mature HGF and the Met ectodomain form 1:1 complexes that can be stabilized with heparin to form a 1:1:1 complex (Gherardi et al, 2003). However, in these experiments, no higher order complexes or aggregates could be detected and the absence of 2:1 complexes suggests two possible scenarios. First, it is possible that the high- and low-affinity binding sites on the receptor overlap. In this case, at a 1:1 molar ratio of ligand and receptor, all high-affinity binding sites on the receptor are occupied and none of the low-affinity binding sites are available, thus preventing the formation of $2: 1$ complexes. Alternatively, the $\alpha$ - and $\beta$-chain of a single HGF molecule bind to the same Met receptor to form stable $1: 1$, but not $2: 1$, complexes. These $1: 1$ complexes can only associate very weakly and require the juxtamembrane or intracellular portion of the receptors, or need additional molecules or co-receptors for the assembly of $2: 2$ or higher order signaling complexes.

Recent crystal structures of dimeric Sema4D and Sema3A have demonstrated how these molecules dimerize. In Sema4D, dimerization of the Sema domains is mediated by four loops that protrude from the core of the propeller. Three of these loops connect strands B4-C4, D4-A5, and B5-C5, and the fourth is part of the insert that follows the fifth blade of the propeller (Figure 4). In our crystal structure, the interface observed in the Semaphorin structures is not present. The superposition of the complex described here and the dimer of Sema4D shows that none of the regions relevant for dimerization in Sema4D are conserved in the Met structure (Figure 5B). Thus, it is unlikely that the Met dimerization follows the Semaphorin paradigm. However, since the loop connecting D4-A5 contains the furin-cleavage site that was altered in our construct, the formal possibility that the dimer seen in Sema4D is similar in the Met receptor system cannot be excluded. A number of characteristics of Met speak against this model. As mentioned earlier, cleavage of Met at the furincleavage site is not required for signaling. Therefore, it seems unlikely that this loop is involved in crucial interactions in the signaling complex. Furthermore, if Met were to dimerize like the semaphorins, the HGF $\beta$-chains would be more than $70 \AA$ apart from each other and lie on opposite sides of the Sema domain. Thus, they could not participate in the stabilization of a 2:2 complex, yet maturation of HGF and the presence of the HGF $\beta$-chain are required for formation of a signaling complex.

A different model for a 2:2 signaling complex is suggested by the crystal packing of the 1:1 complexes in our crystal structure, where two HGF $\beta$-chains form a symmetric interface with about $1250 \AA^{2}$ of total buried surface (Figure 8). This interface is formed via part of the so-called 'activation domain', which distinguishes related active serine proteases from their zymogen precursors (Huber and Bode, 1978). As this dimerization surface is present only in two-chain HGF, the requirement for proteolytic activation of HGF for proper signaling fits this model quite well. The C-termini of the Met receptor Sema domains are separated by about $110 \AA$, a gap that could be easily spanned by the PSI and the four IPT domains of the two receptors that connect the Sema domains to the transmembrane helix. HGF $\beta$-chain/ $\beta$-chain interactions are clearly weak as no oligomers were detected during size exclusion chromatography of the complex and the HGF $\beta$-chain is monomeric in solution (data not shown). Based on these observations, we can propose a model in which the $\alpha$-chain of one- or two-chain HGF first binds Met in the 
A

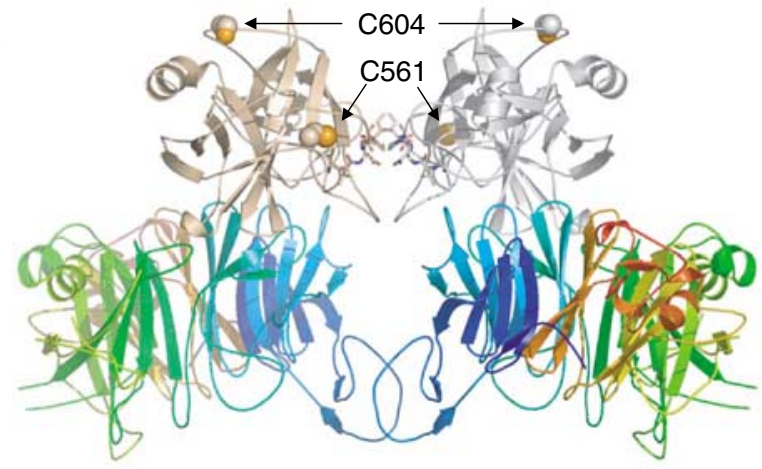

B

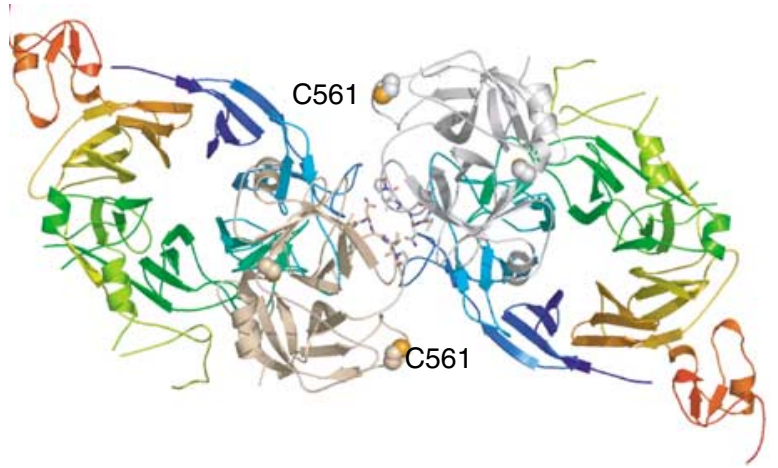

Figure 8 Two different views of two crystallographically related HGF $\beta$-chain:Met complexes that might represent a portion of the active signaling complex. Residues 495:499 of both HGF $\beta$-chains are shown in stick representation to indicate the position of the HGF $\beta$-chain N-termini, the two cysteines (604 and 561) that are candidates for the formation of the disulfide bond with Cys487 in the HGF $\alpha$-chain are shown as spheres.

presence of heparin. If the bound HGF is single chain, cleavage must occur, leading to insertion of the new $\mathrm{N}$ terminus and rearrangements in the 'activation domain' that create the 'low-affinity' Met-binding site on the HGF $\beta$ chain. HGF $\beta$-chain can now bind Met, positioning the $\beta$ chain dimerization surface to contact a neighboring HGF/Met complex.

This 2:2 model is supported by the stoichiometry studies mentioned earlier, which show no dimerization of complexes in solution (Gherardi et al, 2003), indicating that the 2:2 complex formation must be very weak. Also, the fact that the $\alpha$-chain alone (NK4) does not mediate dimerization, but instead acts as an antagonist in vivo (Date et al, 1997), further highlights the potential role for the HGF $\beta$-chain in dimerization. Mutations in the interface between the two HGF $\beta$-chains may, when tested, confirm or refute this hypothesis. Our structure of Met lacks the IPT domains, and their role in the signaling of the Met/HGF complex is still unclear. A crystal structure of the full-length Met in complex with full-length, activated HGF could resolve these issues.

\section{Materials and methods}

\section{Expression and purification of Met}

The cDNA for the full-length Met receptor was kindly provided by $\mathrm{D}$ Wickramasinghe. PCR was carried out on the region encoding residues 25-567 of the Met receptor. A two-step overlapping PCR scheme was used to introduce the thrombin cleavage site (LVPRG) and remove the native sequence (KRKKR). An N-terminal primer added overlapping sequence with the $\mathrm{C}$-terminus of the insect cell secretion signal present in the pAcGP67A vector (BD Biosciences). A C-terminal primer contained coding sequence for $(\mathrm{His})_{8}$ and a NotI restriction site added directly onto the C-terminus. For placement into the pAcGP67A vector, an additional PCR was carried out on the coding region for the insect cell secretion signal, with additional overlapping sequence from the $\mathrm{N}$-terminus of our Met construct. A final PCR was performed to fuse directly the Cterminus of the secretion signal to the N-terminus of our Met construct. This PCR product, as well as pAcGP67A, was digested with SpeI and NotI. The insert was combined with vector at 3:1 ratio, ligated, and transformed into XL-1 Blue cells (Stratagene).

Purified plasmid DNA (pAcGP67A plus Met Sema and PSI domain) was transfected into Sf9 insect cells according to the manufacturer's protocol (BD Biosciences). Viral stock was amplified three times before use in protein expression. For expression, 11 of High Five ${ }^{\mathrm{TM}}$ insect cells (Invitrogen) growing in ESF 921 media (Protein Expression, LLC) at a density of $5 \times 10^{5}$ cells $/ \mathrm{ml}$ was infected with $10 \mathrm{ml}$ of viral stock from the third amplification and incubated at $27^{\circ} \mathrm{C}$ for $72 \mathrm{~h}$. Cells were then removed from the supernatant by centrifugation at $3000 \mathrm{~g}$ for $15 \mathrm{~min}$. In all, $1 \mathrm{mM}$ of $\mathrm{NiCl}_{2}, 5 \mathrm{mM}$ of $\mathrm{CaCl}_{2}$, and $50 \mathrm{mM}$ Tris (pH 8.0) were added to the supernatant. The supernatant was then filtered through a $0.2 \mu \mathrm{m}$ vacuum filter. The supernatant was applied to a $2 \mathrm{ml}$ Ni-NTA column (Qiagen) by gravity flow, followed by $20 \mathrm{ml}$ of wash buffer (50 mM Tris (pH 8.0), $500 \mathrm{mM} \mathrm{NaCl}$, and $5 \mathrm{mM}$ imidazole). Protein was eluted with a buffer containing $50 \mathrm{mM}$ Tris $8.0,300 \mathrm{mM} \mathrm{NaCl}$, and $250 \mathrm{mM}$ imidazole. Fractions containing Met were identified by SDS-PAGE analysis and pooled, concentrated to $500 \mu \mathrm{l}$, and loaded onto a Superdex S-75 gel filtration column (Amersham Biosciences) equilibrated with $50 \mathrm{mM}$ Tris 8.0 and $500 \mathrm{mM} \mathrm{NaCl}$. The final yield for Met (Sema and PSI domain) was approximately $0.25 \mathrm{mg} / \mathrm{l}$ of the insect cell supernatant. The Met full-length ECD (Glu25 to Gln929) domain containing a C-terminal $\mathrm{His}_{6}$ tag was expressed in insect cells and purified by Ni-NTA agarose and gel filtration chromatography using the protocols described above. Met-IgG fusion protein was obtained as previously described (Mark et al, 1992).

\section{Expression and purification of HGF $\beta$}

HGF $\beta$ was expressed in insect cells using baculovirus secretion vector pAcGP67 (BD Biosciences). All constructs contained a $\mathrm{His}_{6}$ tag at the carboxy terminus and were purified by Ni NTA metal chelate and gel filtration chromatography. For HGF $\beta$, a cDNA fragment encoding the HGF $\beta$-chain from residues Val495-Ser728 was cloned by PCR such that Val495 was inserted immediately after the secretion signal sequence. Site-directed mutagenesis was carried out using QuikChange ${ }^{\mathrm{TM}}$ (Stratagene, La Jolla, CA) with oligonucleotide $5^{\prime}$ CCTAATTATGGATCCACAATTCCTG $3^{\prime}$ to make HGF $\beta$, which contains a Cys604 to Ser mutation. HGF $\beta$ mutants Y673A and V692A were made as above in the HGF $\beta$. Transfection of Sf9 cells, amplification, and cell culture were carried out as above. Culture media were harvested by centrifugation at $8000 \mathrm{~g}$ for $15 \mathrm{~min}$ and applied to a $4 \mathrm{ml} \mathrm{Ni-NTA}$ agarose column (Qiagen). Washing and elution were carried out essentially as above. The eluate was pooled and applied to a Superdex ${ }^{\mathrm{TM}}-200$ column (Amersham Biosciences) equilibrated in $10 \mathrm{mM}$ HEPES (pH 7.2), $150 \mathrm{mM} \mathrm{NaCl}$, and $5 \mathrm{mM} \mathrm{CaCl} 2$. Protein peaks were collected and concentrated using a Centriprep ${ }^{\mathrm{TM}}$ YM-10 (Millipore). Fractions were analyzed by SDS-PAGE and protein concentration was determined by quantitative amino-acid analysis. $\mathrm{N}$-terminal sequencing revealed a single correct $\mathrm{N}$-terminus present for HGF $\beta$.

\section{Formation of Met/HGF $\beta$-chain complex}

Met was combined with HGF $\beta$-chain in a $1: 1.5$ ratio and concentrated for loading onto a Superdex S-200 gel filtration column (Amersham Biosciences) equilibrated with $10 \mathrm{mM}$ Tris 8.0 and $250 \mathrm{mM} \mathrm{NaCl}$. Elution fractions were assayed with SDS-PAGE, and those containing the complex were pooled. Buffer exchange into $10 \mathrm{mM}$ Tris 8.0 and $125 \mathrm{mM} \mathrm{NaCl}$ was carried out, and the complex was then concentrated to $10 \mathrm{mg} / \mathrm{ml}$ for crystallization trials. Although crystals grew without deglycosylation, diffraction was enhanced after deglycosylating the Met protein. For this, Met, previously purified using nickel chromatography as described above, was mixed with a combination of PNGase $F$ (Roche) and endoglycosidase A (Roche) at 1:100 enzyme:Met concentration and incubated at room temperature for $3 \mathrm{~h}$. Met was then combined 
with HGF $\beta$-chain, concentrated, and loaded onto a gel filtration column as described above for the nondeglycosylated material.

\section{Crystallization, data collection, and refinement}

Met/HGF $\beta$-chain crystallized at $19^{\circ} \mathrm{C}$ in $4 \mu \mathrm{l}$ hanging drops, consisting of a 1:1 ratio of protein to mother liquor, suspended over mother liquor (12-15\% PEG 10000 , Tris (pH 8.0)). Crystals grew to approximately $100 \mu \mathrm{m} \times 200 \mu \mathrm{m} \times 200 \mu \mathrm{m}$ in 3-7 days. For data collection, crystals were placed in a solution of mother liquor containing $25 \%$ xylitol for $30 \mathrm{~s}$, and then flash frozen in liquid $\mathrm{N}_{2}$.

Data were collected at CHESS beamline A1 to $3.2 \AA$ resolution and processed using the HKL package (Otwinowski and Minor, 1997). The crystals belonged to space group $\mathrm{P} 2_{1} 2_{1} 2$ with cell parameters $a=137.1 \AA, b=186.4 \AA$, and $c=66.7 \AA$, and contained one complex of Met:HGF $\beta$-chain in the asymmetric unit, and thus have a solvent content of about $75 \%$. The structure was solved by molecular replacement with the program AMoRe (Navaza, 1994), with the crystal structure of HGF $\beta$-chain alone (PDB code 1SI5) as a search model. Using data from 8 to $4 \AA$ yielded a clear solution in the rotation and translation functions, and the best solution was subjected to rigid-body refinement in program Refmac (CCP4, 1994). Solvent flattening, which due to the high crystal solvent content led to dramatic improvements in the quality of the phases, yielded maps that were of sufficient quality to recognize the $\beta$ propeller of the Sema domain, and allowed for building the Met receptor without the use of any additional models. Subsequent rounds of model building with program O (Jones et al, 1991) and further refinement with program Refmac resulted in a final model with an $R_{\text {free }}$ and $R_{\text {cryst }}$ of 27.7 and $21.8 \%$, respectively, for all data between 30 and $3.3 \mathrm{~A}$.

HGF $\beta$ and Met-binding affinity by surface plasmon resonance The binding affinity of HGF $\beta$ for Met was determined by surface plasmon resonance using a Biacore 3000 instrument (Biacore Inc.). The Met ECD domain was immobilized on a CM5 chip using amine coupling at $\sim 2000$ resonance units. A series of concentrations of HGF $\beta$ in $10 \mathrm{mM}$ HEPES (pH 7.2), $150 \mathrm{mM} \mathrm{NaCl}, 5 \mathrm{mM} \mathrm{CaCl}_{2}$ ranging from 12.5 to $100 \mathrm{nM}$ were injected at a flow rate of $20 \mu \mathrm{l} /$ min for $40 \mathrm{~s}$. Bound HGF $\beta$ was allowed to dissociate for $10 \mathrm{~min}$.

\section{References}

Antipenko A, Himanen JP, van Leyen K, Nardi-Dei V, Lesniak J, Barton WA, Rajashankar KR, Lu M, Hoemme C, Puschel AW, Nikolov DB (2003) Structure of the semaphorin-3A receptor binding module. Neuron 39: 589-598

Birchmeier C, Birchmeier W, Gherardi E, Vande Woude GF (2003) Met, metastasis, motility and more. Nat Rev Mol Cell Biol 4: 915-925

Bork P, Doerks T, Springer TA, Snel B (1999) Domains in plexins: links to integrins and transcription factors. Trends Biochem Sci 24: 261-263

Chan AM, Rubin JS, Bottaro DP, Hirschfield DW, Chedid M, Aaronson SA (1991) Identification of a competitive HGF antagonist encoded by an alternative transcript. Science 254: $1382-1385$

Cioce V, Csaky KG, Chan AM, Bottaro DP, Taylor WG, Jensen R, Aaronson SA, Rubin JS (1996) Hepatocyte growth factor (HGF)/ NK1 is a naturally occurring HGF/scatter factor variant with partial agonist/antagonist activity. $J$ Biol Chem 271: $13110-13115$

Collaborative Computational Project, N (1994) The CCP4 suite: programs for protein crystallography. Acta Cytstallogr Sect D 50: 760-763

Danilkovitch A, Miller M, Leonard EJ (1999) Interaction of macrophage-stimulating protein with its receptor. J Biol Chem 274: 29937-29943

Date L, Matsumoto K, Shimura H, Tanaka M, Nakamura T (1997) HGF/NK4 is a specific antagonist for pleiotrophic actions of hepatocyte growth factor. FEBS Lett 520: 1-8

DeLano WL (2002) The PyMOL Molecular Graphics System on World Wide Web http://www.pymol.org

de Vos AM, Ultsch M, Kossiakoff AA (1992) Human growth hormone and extracellular domain of its receptor: crystal structure of the complex. Science 255: 306-312
Appropriate background subtraction was carried out. The association $\left(k_{\text {on }}\right)$ and dissociation $\left(k_{\text {off }}\right)$ rate constants were obtained by a global fitting program provided with the instrument; the ratio $k_{\text {off }} /$ $k_{\text {on }}$ was used to calculate the dissociation constant $\left(K_{\mathrm{d}}\right)$.

\section{Binding of HGF mutants to Met}

Wild-type HGF $\beta$ was biotinylated using a 20 -fold molar excess of biotin-maleimide (Pierce) at room temperature for $2 \mathrm{~h}$. Microtiter plates (Nunc) were coated overnight at $4^{\circ} \mathrm{C}$ with $2 \mu \mathrm{g} / \mathrm{ml}$ of rabbit anti-human IgG Fc-specific antibody (Jackson ImmunoResearch Laboratory) in $50 \mathrm{mM}$ sodium carbonate buffer (pH 9.6). After blocking with $1 \%$ BSA in HBS buffer (50 mM HEPES (pH 7.2), $150 \mathrm{mM} \mathrm{NaCl}, 5 \mathrm{mM} \mathrm{CaCl} 2$, and $0.1 \%$ Tween-20), $1 \mu \mathrm{g} / \mathrm{ml} \mathrm{Met-IgG}$ fusion protein (Mark et al, 1992) was added and plates were incubated for $1 \mathrm{~h}$ with gentle shaking at room temperature. After washing with HBS buffer, $250 \mathrm{nM}$ biotinylated wild-type HGF $\beta$ and various concentrations of unlabeled HGF $\beta$ or variants were added. After incubation for $1 \mathrm{~h}$ at room temperature, the amount of biotinylated wild-type HGF $\beta$ bound on the plate was detected using HRP-neutravidin (Pierce, Rockford, IL), followed by addition of $\mathrm{TMB} / \mathrm{H}_{2} \mathrm{O}_{2}$ substrate (KPL, Gaithersburg, MD). The reaction was stopped with $1 \mathrm{M} \mathrm{H}_{3} \mathrm{PO}_{4}$ and the $A_{450}$ was measured on a Molecular Devices SpectraMax Plus ${ }^{384}$ microplate reader. Concentrations to give half-maximal inhibition $\left(\mathrm{IC}_{50}\right.$ ) were determined by a fourparameter fit using Kaleidagraph.

\section{Acknowledgements}

We thank Charles Eigenbrot, Fernando Bazan, and Dineli Wickramasinghe for discussions, and Bart de Vos for his support. We thank the oligonucleotide synthesis, DNA sequencing, and protein sequencing groups for their excellent support. Data were collected at CHESS, which is supported by the National Science Foundation under award DMR 97-13424, which is supported by award RR-01646 from the National Institutes of Health, through its National Center for Research Resources. Coordinates and structure factors have been deposited in the RCSB Protein Data Bank (accession code $1 \mathrm{SHY}$ ).
Donate LE, Gherardi E, Srinivasan N, Sowdhamini R, Aparicio S, Blundell TL (1994) Molecular evolution and domain structure of plasminogen-related growth factors (HGF/SF and HGF1/MSP). Protein Sci 3: 2378-2394

Freer ST, Kraut J, Robertus JD, Wright HT, Xuong NH (1970) Chymotrypsinogen: 2.5-angstrom crystal structure, comparison with alpha-chymotrypsin, and implications for zymogen activation. Biochemistry 9: 1997-2009

Gherardi E, Youles ME, Miguel RN, Blundell TL, Iamele L, Gough J, Bandyopadhyay A, Hartmann G, Butler PJ (2003) Functional map and domain structure of Met, the product of the c-met protooncogene and receptor for hepatocyte growth factor/scatter factor. Proc Natl Acad Sci USA 100: 12039-12044

Hartmann G, Naldini L, Weidner KM, Sachs M, Vigna E, Comoglio PM, Birchmeier W (1992) A functional domain in the heavy chain of scatter factor/hepatocyte growth factor binds the c-Met receptor and induces cell dissociation but not mitogenesis. Proc Natl Acad Sci USA 89: 11574-11578

Hedstrom L (2002) Serine protease mechanism and specificity. Chem Rev 102: 4501-4524

Huber R, Bode W (1978) Structural basis of the activation and action of trypsin. Acc Chem Res 11: 114-122

Huff JL, Jelinek MA, Borgman CA, Lansing TJ, Parsons JT (1993) The protooncogene $c$-sea encodes a transmembrane proteintyrosine kinase related to the Met/hepatocyte growth factor/ scatter factor receptor. Proc Natl Acad Sci USA 90: 6140-6144

Jankowski K, Kucia M, Wysoczynski M, Reca R, Zhao D, Trzyna E, Trent J, Peiper S, Zembala M, Ratajczak J, Houghton P, JanowskaWieczorek A, Ratajczak MZ (2003) Both hepatocyte growth factor (HGF) and stromal-derived factor-1 regulate the metastatic behavior of human rhabdomyosarcoma cells, but only HGF enhances their resistance to radiochemotherapy. Cancer Res 63: 7926-7935 
Jones TA, Zou JY, Cowan SW, Kjeldgaard M (1991) Improved methods for building protein models in electron density maps and the location of errors in these models. Acta Crystallogr Sect A 47: 110-119

Kataoka H, Miyata S, Uchinokura S, Itoh H (2003) Roles of hepatocyte growth factor (HGF) activator and HGF activator inhibitor in the pericellular activation of $\mathrm{HGF} / \mathrm{scatter}$ factor. Cancer Metastasis Rev 22: 223-236

Komada M, Hatsuzawa K, Shibamoto S, Ito F, Nakayama K, Kitamura N (1993) Proteolytic processing of the hepatocyte growth factor/scatter factor receptor by furin. FEBS Lett 328: 25-29

Laskowski RA, MacArthur MW, Moss DS, Thornton JM (1993) PROCHECK - a program to check the stereochemical quality of protein structures. J Appl Crystallogr 26: 283-291

Lietha D, Chirgadze DY, Mulloy B, Blundell TL, Gherardi E (2001) Crystal structures of NK1-heparin complexes reveal the basis for NK1 activity and enable engineering of potent agonists of the MET receptor. EMBO J 20: 5543-5555

Lokker NA, Mark MR, Luis EA, Bennett GL, Robbins KA, Baker JB, Godowski PJ (1992) Structure-function analysis of hepatocyte growth factor: identification of variants that lack mitogenic activity yet retain high affinity receptor binding. EMBO J 11: 2503-2510

Love CA, Harlos K, Mavaddat N, Davis SJ, Stuart DI, Jones EY, Esnouf RM (2003) The ligand-binding face of the semaphorins revealed by the high-resolution crystal structure of Sema4D. Nat Struct Biol 10: 843-848

Ma PC, Maulik G, Christensen J, Salgia R (2003) c-Met: structure, functions and potential for therapeutic inhibition. Cancer Metastasis Rev 22: 309-325

Mark MR, Lokker NA, Zioncheck TF, Luis EA, Godowski PJ (1992) Expression and characterization of hepatocyte growth factor receptor-IgG fusion proteins. Effects of mutations in the potential proteolytic cleavage site on processing and ligand binding. J Biol Chem 267: 26166-26171

Miller M, Leonard EJ (1998) Mode of receptor binding and activation by plasminogen-related growth factors. FEBS Lett 429: $1-3$

Montesano R, Matsumoto K, Nakamura T, Orci L (1991) Identification of a fibroblast-derived epithelial morphogen as hepatocyte growth factor. Cell 67: 901-908

Nakamura T, Nishizawa T, Hagiya $M$, Seki $T$, Shimonishi $M$, Sugimura A, Tashiro K, Shimizu S (1989) Molecular cloning and expression of human hepatocyte growth factor. Nature $\mathbf{3 4 2}$ : 440-443

Nardone HC, Ziober AF, LiVolsi VA, Mandel SJ, Baloch ZW, Weber RS, Mick R, Ziober BL (2003) C-Met expression in tall cell variant papillary carcinoma of the thyroid. Cancer 98: 1386-1393

Navaza J (1994) AMoRe: an Automated Package for Molecular Replacement. Acta Crystallogr Sect A 50: 157-163

Otwinowski Z, Minor W (1997) Processing of X-ray diffraction data collected in oscillation mode. Methods Enzymol 276: 307-326

Perona JJ, Craik CS (1995) Structural basis of substrate specificity in the serine proteases. Protein Sci 4: 337-360

Prat M, Crepaldi T, Pennacchietti S, Bussolino F, Comoglio PM (1998) Agonistic monoclonal antibodies against the Met receptor dissect the biological responses to HGF. J Cell Sci 111: 237-247

Ronsin C, Muscatelli F, Mattei MG, Breathnach R (1993) A novel putative receptor protein tyrosine kinase of the met family. Oncogene 8: 1195-1202

Rosen EM, Nigam SK, Goldberg ID (1994) Scatter factor and the cmet receptor: a paradigm for mesenchymal/epithelial interaction. J Cell Biol 127: 1783-1787

Sonnenberg E, Meyer D, Weidner KM, Birchmeier C (1993) Scatter factor/hepatocyte growth factor and its receptor, the c-met tyrosine kinase, can mediate a signal exchange between mesenchyme and epithelia during mouse development. J Cell Biol 123: 223-235

Takagi S, Murakami Y, Kasuya Y, Tanaka H, Kawakami A, Mizutani A, Ohta K, Fujisawa H (1995) Plexin: a novel neuronal cell surface molecule that mediates cell adhesion via a homophilic binding mechanism in the presence of calcium ions. Neuron 14: 1189-1199

Trusolino L, Comoglio PM (2002) Scatter-factor and semaphorin receptors: cell signalling for invasive growth. Nat Rev Cancer $\mathbf{2}$ 289-300

Winberg ML, Noordermeer JN, Tamagnone L, Comoglio PM, Spriggs MK, Tessier-Lavigne M, Goodman CS (1998) Plexin A is a neuronal semaphorin receptor that controls axon guidance. Cell 95: 903-916

Xiong JP, Stehle T, Zhang R, Joachimiak A, Frech F, Goodman SL, Arnaout MA (2002) Crystal structure of the extracellular segment of integrin alpha V 33 in complex with an Arg-Gly-Asp ligand. Science 296: 151-155

Zhang YW, Vande Woude GF (2003) HGF/SF-met signaling in the control of branching morphogenesis and invasion. J Cell Biochem 88: $408-417$ 